\title{
Komunikasi Verbal dan Nonverbal dalam Game Online League of Legends
}

\author{
Ivander Stefanus, Wulan Purnama Sari \\ ivanderxlc@gmail.com,wulanp@fikom.untar.ac.id \\ Fakultas Ilmu Komunikasi Universitas Tarumanagara
}

\begin{abstract}
91\% of Indonesian people use mobile phones in their daily lives and $22 \%$ of the entire people use laptops or computers in their daily lives and not infrequently they also play games from their gadgets or computers. Game is known as a mere intermezo, but with globalization game that should've been entertainment to drive away fatigue after daily activities has growing rapidly to become competitive with the existence of online games. In team-based online games one of the factors to achieve victory is communication because with communication players can produce synergies and a plan to win the game. In analyzing this study, author uses the theory of verbal and nonverbal communication between players in League of Legends, in order to find out the forms of verbal and nonverbal communication between players in League of Legends. The main theory in this study is the theory of verbal and nonverbal communication. This Research use a qualitative approach that is descriptive and using phenomenology method. Phenomenology methods connect scientific knowledge with everyday experience, and from the activities where the experience and knowledge originate. The results of this study indicate that in League of Legends, there are verbal communication in the form of in-game chat, voice chat, and through Discord. Whereas nonverbal communication is in the form of smart ping, and emotes.
\end{abstract}

Keywords: nonverbal communication, online, game, verbal communication.

\begin{abstract}
Abstrak
Sebanyak 91\% masyarakat Indonesia menggunakan handphone dalam kehidupan sehari-hari serta sebanyak $22 \%$ masyarakat menggunakan laptop atau komputer dalam kehidupan sehari-hari mereka dan tak jarang pula mereka memainkan game dari gadget atau komputer mereka. Game lebih decanal sebagai sebuah intermezo belaka, namun seiring berkembangnya zaman game yang seharusnya menjadi hiburan untuk mengusir penat setelah aktivitas sehari-hari secara pesat telah berkembang menjadi kompetitif dengan adanya game online. Dalam game online berbasis tim salah satu faktor untuk mencapai kemenangan dalam game adalah komunikasi karena dengan adanya komunikasi maka tim dapat menghasilkan sinergi dan rencana yang matang untuk memenangkan game. Rumusan masalah dalam penelitian ini adalah bagaimana bentuk komunikasi verbal dan nonverbal di antara pemain dalam game online League of Legends. Teori utama dalam penelitian ini adalah teori komunikasi verbal dan nonverbal. Peneliti menggunakan pendekatan kualitatif yang bersifat deskriptif dan metode fenomenologi. Fenomenologi menghubungkan antara pengetahuan ilmiah dengan pengalaman sehari-hari, dan dari kegiatan dimana pengalaman dan pengetahuan itu berasal. Hasil dari penelitian ini menunjukan bahwa dalam game League of Legends terdapat saluran komunikasi verbal yaitu berupa in-game chat, voice chat, dan melalui Discord. Sedangkan komunikasi nonverbal berupa smart ping, dan emotes.
\end{abstract}


Kata Kunci : komunikasi verbal, komunikasi nonverbal, game online.

\section{Pendahuluan}

Game Online telah berkembang pesat dalam beberapa tahun belakangan ini, tidak hanya dapat dimainkan di komputer tetapi juga dapat dimainkan melalui Smartphone. Menurut Bobby Bodenheimer (dalam Dianty, 2012) game online adalah sebuah program permainan yang tersambung oleh jaringan yang bisa dimainkan kapanpun, dimanapun dan dapat dimainkan bersamaan berkelompok di seluruh dunia dan permainan itu sendiri menampilkan gambar-gambar menarik seperti yang diinginkan, yang didukung oleh komputer .

League of Legends merupakan game yang dikembangkan dan dipublikasikan oleh Riot Games pada 27 Oktober 2009. League of Legends adalah permainan strategi dengan basis tim di mana dua tim dari lima champion (julukan terhadap karakter dalam game) yang kuat berhadapan untuk menghancurkan markas yang lain. Dari penjelasan tersebut dapat disimpulkan bahwa League of Legends adalah Game dengan genre MOBA (Multiplayer Online Battle Arena). Dilansir dari esporsnesia.com Game MOBA merupakan permainan dimana pemain memainkan sebuah karakter di dalam game sebagai sebuah tim dan menghancurkan bangunan inti lawan untuk mencapai kemenangan.

Dalam game online berbasis tim terdapat banyak faktor untuk mencapai kemenangan dalam bermain game salah satunya adalah komunikasi yang terjalin di dalam game tersebut alasannya adalah dengan adanya komunikasi dalam tim maka tim dapat menghasilkan sinergi dan rencana yang matang dan juga memutuskan langkah selanjutnya untuk memenangkan game.

Komunikasi adalah penyampaian simbol yang dapat dimengerti oleh pengirim atau sumber pesan dan penerima pesan. Penyampaian komunikasi dapat dilakukan dengan berbagai yaitu secara verbal, nonverbal maupun gabungan antara verbal dan nonverbal. Komunikasi verbal merupakan dimana komunikan berkomunikasi dengan komunikator melalui pesan tertulis maupun lisan. Bagi kebanyakan orang komunikasi verbal adalah satu-satunya bentuk komunikasi namun pada kenyataan tersebut terdapat bentuk komunikasi nonverbal. Menurut Barata dalam Solihin (2015) menyampaikan bahwa: "Komunikasi nonverbal adalah komunikasi yang diungkapkan lewat objek di setiap kategori lainnya (the object language), komunikasi menggunakan gerak (gesture) sebagai sinyal (sign language), serta komunikasi melalui tindakan atau gerakan tubuh (action language)".

Penelitian ini bertujuan untuk mengetahui komunikasi verbal pada pemain game online League of Legends dan mengetahui komunikasi nonverbal pemain game online League of Legends.

Salah satu penelitian terdahulu dilakukan oleh Valentina (2018) yang menunjukan hasil penelitian memperlihatkan pola komunikasi antara sesama pemain, memiliki saluran komunikasi verbal yaitu discord, microphone dan voice chat. Sedangkan saluran komunikasi non verbal berupa sticker, emoji.

\section{Metode Penelitian}

Penelitian ini dilakukan dengan menggunakan metode kualitatif dan menggunakan metode analisis fenomenologi. Fenomenologi menghubungkan antara pengetahuan ilmiah dengan pengalaman sehari-hari, dan dari kegiatan dimana 
pengalaman dan pengetahuan itu berasal. Metode pengumpulan data yang penulis gunakan yaitu wawancara mendalam, observasi, dokumentasi, studi kepustakaan, dan penelusuran data online.

Teknik pengolahan dan analisis data yang penulis gunakan adalah teori Miles dan Huberman dalam bentuk pengumpulan data, reduksi data, penyajian data, dan penarikan kesimpulan.

Teknik keabsahan data yang penulis gunakan adalah triangulasi. Moleong (2010) mendefinisikan triangulasi sebagai teknik yang digunakan peneliti dengan cara memanfaatkan sesuatu di luar data penelitian sebagai pembanding data guna memeriksa keabsahan data penelitian (Risma, 2014). Peneliti menggunakan triangulasi agar peneliti dapat membandingkan data yang telah didapat dari wawancara dengan data yang didapat dari sumber lain seperti internet.

Pada penelitian ini peneliti melakukan wawancara degan 4 narasumber yaitu (1) Dinda Kirana seorang mahasiswi seorang pemain League of Legends kurang lebih selama 4 tahun; (2) Aldino Putra Widyawan seorang pemain League of Legends selama kurang lebih 6 tahun, ia juga merupakan Kepala Bidang Bagian Event IESPA (Indonesia Esport Association) Regional Jakarta; (3) Billsen Farlen seorang mahasiswa 21 tahun yang telah bermain sejak 2013 atau kurang lebih 7 tahun lamanya bermain League Of Legends; (4) Richard Kusuma mahasiswa 22 tahun yang telah bermain League Of Legends sejak 2013 atau kurang lebih 7 tahun bermain League Of Legends

\section{Hasil Temuan dan Diskusi}

Berdasarkan keempat narasumber di atas yang penulis wawancarai, dapat disimpulkan bahwa komunikasi antar pemain dalam game online League of Legends terdapat saluran komunikasi verbal dalam bentuk fitur in-game chat, voice chat dan Discord.

\section{- In-game chat}

In-game chat merupakan fitur komunikasi yang telah tersedia jika telah memasuki permainan. Pemain hanya perlu menekan tombol enter pada keyboard dan menuliskan apa yang ingin disampaikan lalu dikirimkan kepada pemain satu tim atau kepada seluruh pemain yang sedang bermain saat itu untuk saling berkomunikasi serta memberikan arahan saat bermain. In-game chat tidak hanya dapat digunakan untuk berkomunikasi terhadap pemain yang berada di dalam game namun juga dapat digunakan untuk berkomunikasi kepada pemain teman lain yang sedang tidak sedang bermain dalam 1 permainan dengan menggunakan " $/ w$ atau /msg summoners name" (summoners adalah panggilan kepada pemain League Of Legends) untuk berkomunikasi kepada teman lain yang sedang tidak sedang bermain dalam 1 permainan dan menggunakan command "/r" untuk membalas pesan jika pemain sedang berada dalam game. Namun pemain juga dapat memilih untuk tidak membaca atau tidak menerima pesan dari pemain lain dengan cara me-mute pemain tersebut melalui scoreboard atau jika ingin me-mute seluruh pemain maka dapat menggunakan command "/mute all" 
Gambar 1. Contoh In-game Chat

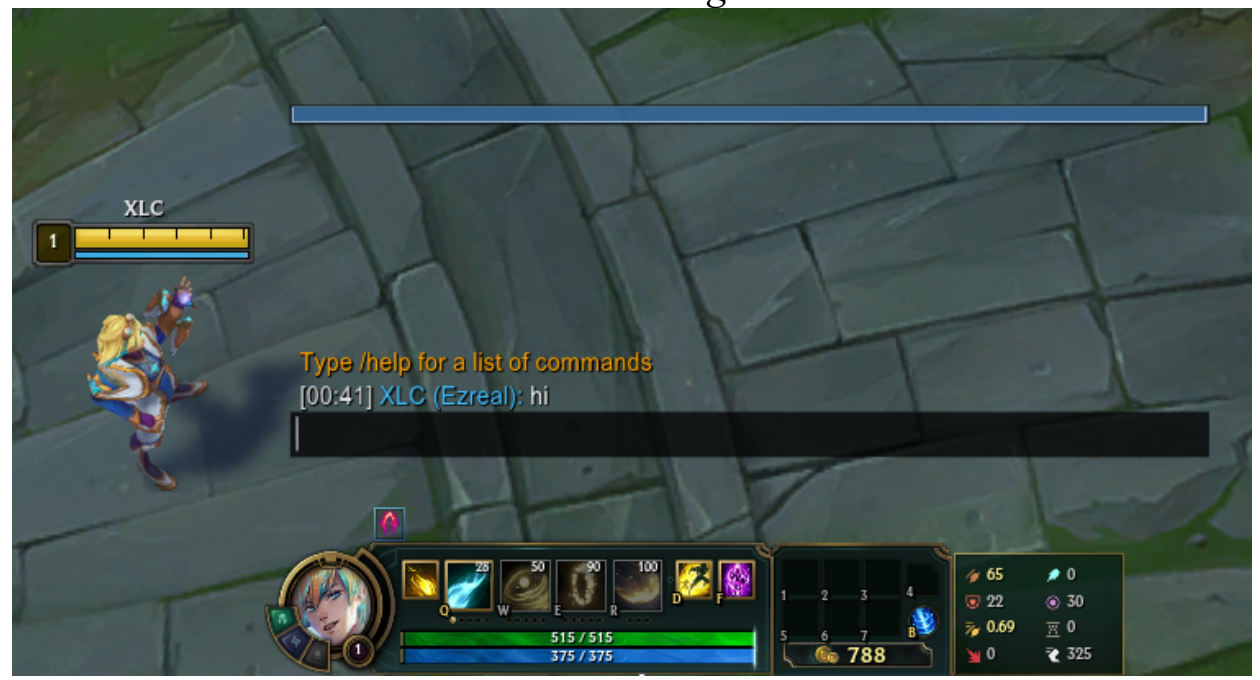

Sumber: Dokumentasi Pribadi

\section{- Voice Chat}

Voice chat merupakan fitur di dalam game yang dapat digunakan oleh pemain jika pemain tersebut telah ikut dalam party lalu dengan otomatis pemain dapat saling berbicara satu sama lain saat permainan berlangsung.

- Discord

Discord yang memiliki fungsi yang sama dengan voice chat yang telah disediakan oleh League of Legends namun melalui aplikasi yang berbeda. Discord merupakan sebuah aplikasi chatting yang memiliki kemiripan dengan aplikasi seperti Skype, Zoom, dan Hangouts yang dapat digunakan untuk chatting, video call dan voice call, namun Discord lebih dikhususkan teruntuk para kalangan gamers.

Sedangkan dalam game online League of Legends terdapat saluran komunikasi nonverbal dalam bentuk fitur smart ping dan emotes.

- Smart Ping

Smart ping merupakan sebuah menu radial yang memiliki empat (4) macam tanda/sinyal. Smart ping dapat digunakan untuk berkomunikasi dengan tim lebih cepat daripada menghabiskan waktu untuk mengetik dan mengganggu jalannya permainan. Keempat tanda/sinyal tersebut memiliki simbol dan suara yang berbeda ketika digunakan, keempat tanda/sinyal tersebut digunakan pada waktu tertentu tergantung situasi yang sedang dihadapi oleh tim.

Gambar 2. Contoh smart ping 


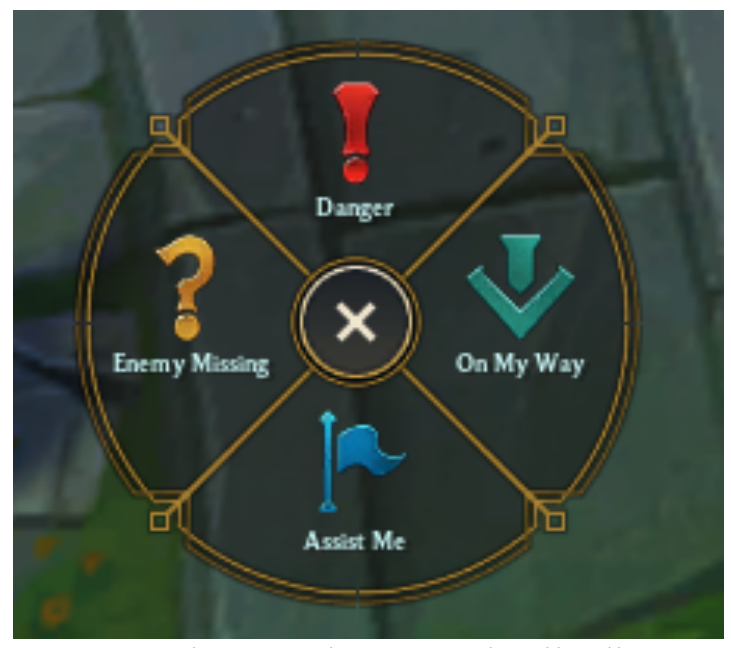

Sumber : Dokumentasi pribadi

- Danger Ping

Danger ping digunakan untuk memberi tahu kepada rekan tim bahwa tindakan yang ia lakukan, tempat yang ia akan tuju berbahaya ataupun untuk memperingati untuk tidak mendekati musuh karena akan tidak menguntungkan untuk tim.

- On My Way Ping biasanya digunakan oleh jungler tim yang akan pergi ke salah satu lane untuk membantu dan menandakan bahwa ia akan segera datang untuk melakukan gank. Namun gank tidak hanya dilakukan oleh jungler seorang gank juga dapat dilakukan oleh toplaner ataupun midlaner untuk membantu tim.

- Assist Me Ping digunakan ketika pemain membutuhkan bantuan untuk menghadapi musuh atau pemain meminta temannya untuk berada di dekat dekatnya.

- Enemy Missing Ping digunakan ketika musuh anda tidak terlihat atau menghilang, kegunaan ping ini adalah untuk memberi tahu teman satu tim bahwa mereka perlu waspada agar tidak di-gank oleh musuh.

\section{- Emotes}

Emotes merupakan sebuah emoticon untuk mengungkapkan emosi/ perasaan yang ingin diungkapkan antar sesama pemain pada saat permainan berlangsung atau juga dapat digunakan untuk memprovokasi tim lawan dengan menunjukan emotes yang menjengkelkan.

Gambar 3. Contoh Emotes 


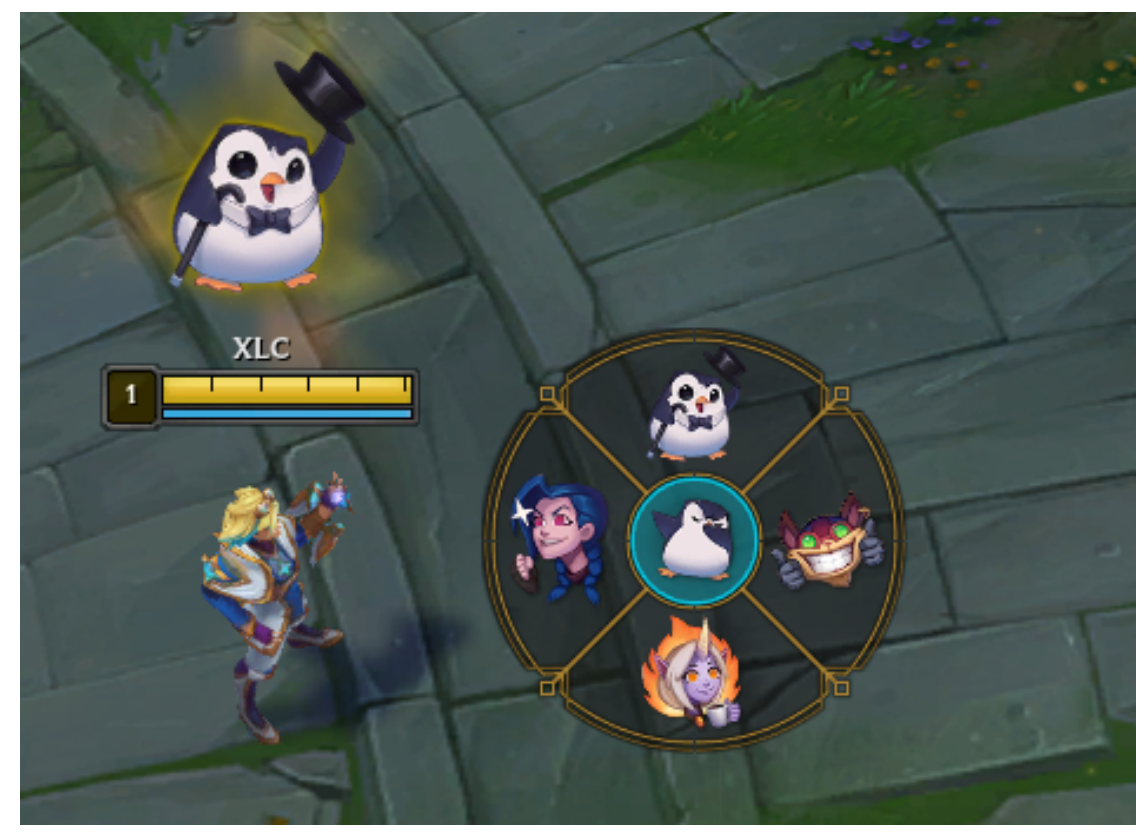

Sumber : Dokumentasi Pribadi

Berdasarkan hasil di atas, komunikasi verbal dalam League of Legends terjadi tidak hanya ketika pemain sedang dalam permainan melalui in-game chat ataupun melalui voice chat, namun pemain juga dapat saling berinteraksi satu sama lain ketika tidak bermain melalui sistem chat yang tersedia di client. Sedangkan untuk komunikasi nonverbal antar pemain menggunakan smart ping dan emotes hanya dapat digunakan didalam game saja.

\section{Simpulan}

Berdasarkan hasil dari penelitian kualitatif mengenai studi komunikasi verbal dan nonverbal pemain game online League of Legends, dapat dinyatakan bahwa dalam game online League of Legends terdapat saluran komunikasi verbal berupa ingame chat, voice chat, dan discord sedangkan komunikasi nonverbal yang terjalin melalui smart ping dan emotes.

\section{Ucapan Terima Kasih}

Pada kesempatan ini peneliti mengucapkan rasa syukur dan terima kasih kepada keluarga peneliti dan juga kepada teman, sahabat, dan narasumber penelitian, serta pihak-pihak lain yang telah membantu dalam proses penyelesaian penelitian ini.

\section{Daftar Pustaka}

Dianty, N. (2012). Dampak Game Online Terhadap Kesehatan Remaja (Studi di Fajar Net Raden Intan Bandar Lampung). Universitas Lampung.

Risma, A. (2014). Strategi Museum Perjuangan Kota Yogyakarta Dalam Meningkatkan Minat Pengunjung. Universitas Negeri Yogyakarta

Solihin, O. (2015). Makna Komunikasi Non Verbal Dalam Tradisi Sarungan Di Pondok Pesantren Tradisional Di Kota Bandung. 
Ivander Stefanus, Wulan Purnama Sari: Komunikasi Verbal dan Nonverbal dalam

Game Online League of Legends

Valentina, E., \& Sari, W. P. (2018). Studi Komunikasi Verbal dan Non Verbal Game Mobile Legends: Bang Bang. Jurnal Koneksi, 2(2), 300. Retrieved from : https://doi.org/10.24912/kn.v2i2.3899 